\title{
Initial assessment of metallurgical interaction of clad/base metal systems
}

Applied Materials Division 


\title{
About Argonne National Laboratory
}

Argonne is a U.S. Department of Energy laboratory managed by UChicago

Argonne, LLC under contract DE-AC02-06CH11357. The Laboratory's main facility

is outside Chicago, at 9700 South Cass Avenue, Argonne, Illinois 60439. For

information about Argonne

and its pioneering science and technology programs, see www.anl.gov.

\section{DOCUMENT AVAILABILITY}

Online Access: U.S. Department of Energy (DOE) reports produced after 1991 and a growing number of pre-1991 documents are available free at OSTI.GOV (http://www.osti.gov/), a service of the US Dept. of Energy's Office of Scientific and Technical Information.

Reports not in digital format may be purchased by the public from the National Technical Information Service (NTIS):

U.S. Department of Commerce

National Technical Information

Service 5301 Shawnee Rd

Alexandria, VA 22312

www.ntis.gov

Phone: (800) 553-NTIS (6847) or (703) 605-6000

Fax: (703) 605-6900

Email: orders@ntis.gov

Reports not in digital format are available to DOE and DOE contractors from the Office of Scientific and Technical Information (OSTI):

U.S. Department of Energy

Office of Scientific and Technical Information

P.O. Box 62

Oak Ridge, TN 37831-0062

www.osti.gov

Phone: (865) 576-8401

Fax: (865) 576-5728

Email: reports@osti.gov

\begin{abstract}
Disclaimer
This report was prepared as an account of work sponsored by an agency of the United States Government. Neither the United States Government nor any agency thereof, nor UChicago Argonne, LLC, nor any of their employees or officers, makes any warranty, express or implied, or assumes any legal liability or responsibility for the accuracy, completeness, or usefulness of any information, apparatus, product, or process disclosed, or represents that its use would not infringe privately owned rights. Reference herein to any specific commercial product, process, or service by trade name, trademark, manufacturer, or otherwise, does not necessarily constitute or imply its endorsement, recommendation, or favoring by the United States Government or any agency thereof. The views and opinions of document authors expressed herein do not necessarily state or reflect those of the United States Government or any agency thereof, Argonne National Laboratory, or UChicago Argonne, LLC.
\end{abstract}




\section{Initial assessment of metallurgical interaction of clad/base metal systems}

Prepared by

G.A. Young, Dominion Engineering, Inc.

T.-L. Sham, Argonne National Laboratory

September 2018 



\begin{abstract}
Molten Salt Reactors (MSRs), both liquid fuel and sold fuel (e.g., the fluoride salt-cooled high temperature reactors, FHR's) offer several advantages relative to conventional, water-cooled nuclear power systems. However, currently approved ASME structural materials have not been optimized for use in molten salt environments and demonstrating materials performance in molten salts is challenging. Toward the goal of enabling MSR designs, corrosion resistant claddings offer an attractive solution to help mitigate corrosion concerns and enable the use of approved ASME materials. This report assesses metals and alloys that may be effective as corrosion resistant cladding with select structural alloys. The structural alloys of interest are capable of use at high temperatures $\geq 600^{\circ} \mathrm{C}$ for times $\geq 100,000$ hours. Potential cladding alloys were assessed based on their corrosion resistance in both chloride and fluoride based salts, physical properties, mechanical properties, nuclear performance, and resistance to environmental-assisted cracking. Additionally both thermodynamic and kinetic computational modeling were used to assess interactions between the base metal and the cladding. Results to date have identified three candidate alloy systems that help enable MSR designs; nickel, molybdenum, and tungsten based claddings. This report discusses pros and cons of each class of cladding and outlines future work to develop these base metal / clad systems into industrial products suitable for use in commercial nuclear power systems.
\end{abstract}





\section{Table of Contents}

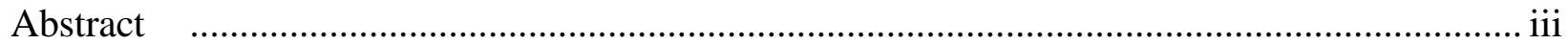

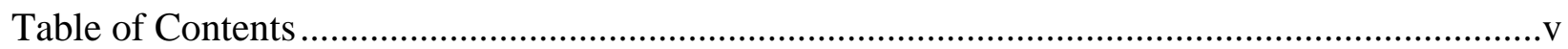

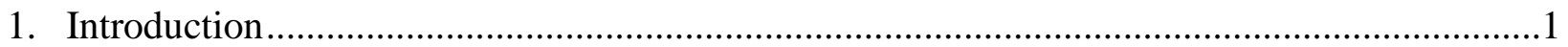

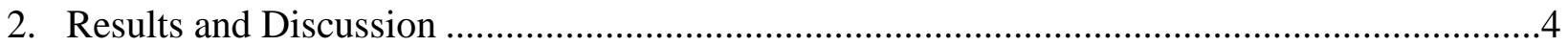

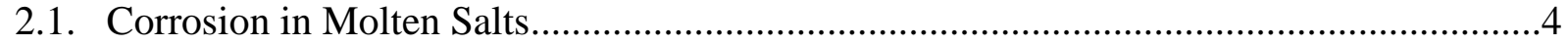

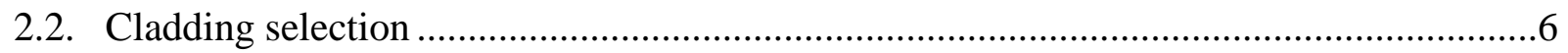

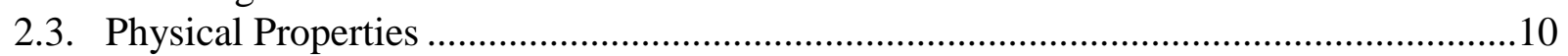

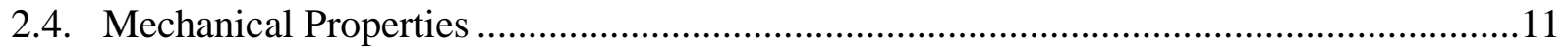

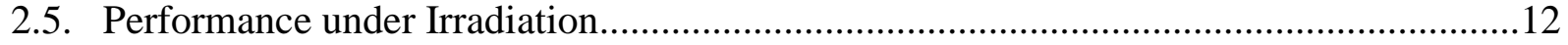

2.6. Metallurgical Compatibility ....................................................................................13

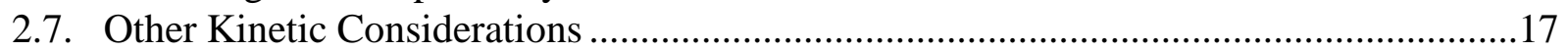

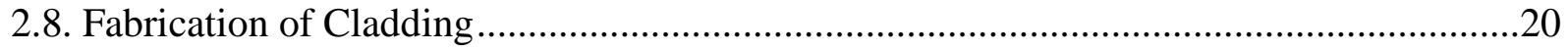

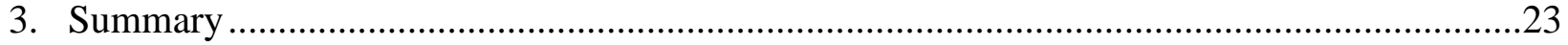

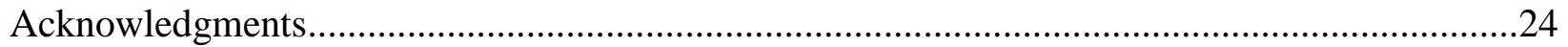

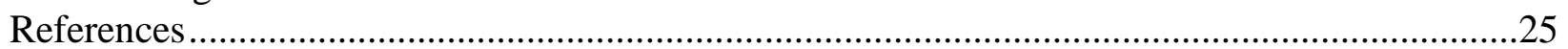

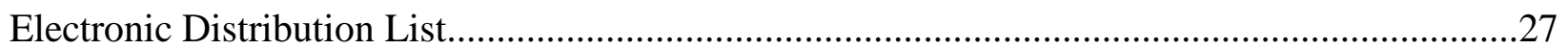





\section{List of Figures}

Figure 1-1. Schematic Illustration of a liquid fueled molten salt reactor system (MSR) from

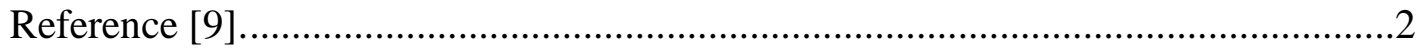

Figure 1-2. Schematic Illustration of a fluoride cooled high temperature reactor system (FHR) from

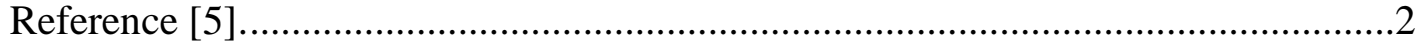

Figure 2-1. Comparison of calculated redox potentials in fluoride (left) and chloride (right) molten salt. The potential of chromium is highlighted in red and metals more noble to chromium are shaded green

Figure 2-2. Summary of tradeoffs with several metals that could be used for corrosion resistant cladding

Figure 2-3. Illustration of the methodology used to assess the metallurgical compatibility of selected ASME base metals and candidate cladding alloys for corrosion resistance in molten salts.

Figure 2-4. Comparison of binary phase diagrams for base metals (Fe and $\mathrm{Ni}$ ) and candidate cladding (Ni, Mo, W) alloys. The red areas highlight FHR and MSR operating temperatures.

Figure 2-5. Illustration of the effects of dilution with nickel (left) and molybdenum (right) on the phase stability of a Fe-Ni-Cr alloy near the 316 stainless steel composition. .15

Figure 2-6. Illustration of the effects of molybdenum dilution on the solidification behavior of $316 \mathrm{H}$ (left) and on the phase stability (right)....

Figure 2-7. Comparison of the time-temperature-transformation kinetics for the sigma, chi, and laves phases in $316 \mathrm{H}$ stainless steel (left) with the same alloy diluted with $20 \mathrm{wt} \%$ molybdenum (right).

Figure 2-8. Diffusion data for nickel, molybdenum, and tungsten in chromium (left) and estimated diffusion distance after 40 years at $700^{\circ} \mathrm{C}$ (right).

Figure 2-9. Estimated interdiffusion provides for nickel and tungsten in FCC iron after 60 years at $750^{\circ} \mathrm{C}$.

Figure 2-10. Summary of tradeoffs with several metals that could be used for corrosion resistant cladding 

List of Tables

Table 1-1. Comparison of Potential FHR and MSR Operating Conditions with Conventional PWR

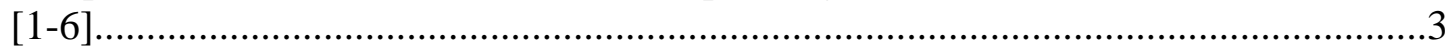

Table 2-1. Summary of Potential Metals Considered for Corrosion Resistant Cladding in Molten Salt Reactor Applications.

Table 2-2. Recommended Alloys to Assess as Corrosion Resistant Cladding for Molten Salt Reactor Applications.

Table 2-3. Comparison of Physical Properties of Candidate Cladding Alloys and Structural Alloys [29, 34-38].

Table 2-4. Comparison of Mechanical Properties of Candidate Cladding Alloys and Structural Alloys [29, 34-38].

Table 2-5. Comparison of Selected Irradiation Behavior for Candidate Cladding Alloys.

Table 2-6. Comparison of the Ability to Fabricate Candidate Corrosion Resistant Claddings via Several Industrial Processes. 


\section{Introduction}

The Generation IV molten salt reactor concepts, both based on liquid fuel (MSR's, Figure 11) or solid fuel (fluoride salt-cooled high temperature reactors, FHR, Figure 1-2), have several desirable attributes and intrinsic safety advantages relative to conventional light water reactors. For example, MSR and FHR designed to operate at relatively low pressure can tolerate high temperatures due to the high boiling point of the molten salts, and many designs display a negative temperature coefficient of reactivity. Furthermore, FHR's typically use high temperature capable fuel (e.g. TRISO fuel particles) and MSR's can be passively shutdown via melting of 'freeze plugs'. A comparison of some key features between light water reactors, MSR's, and FHR's is shown in Table 1-1, which highlights their low operating pressure and higher temperature of operation relative to water cooled reactors as well as the wide range of expected irradiation of core internals from $\sim 1$ dpa in some FHR concepts where graphite provides significant shielding to 200 dpa in liquid fueled designs [1-6].

Despite these advantages, the higher temperature of operation and potentially aggressive environment of molten salt present significant challenges to structural materials that are currently code qualified for high temperature nuclear use. For example, ASME Boiler and Pressure Vessel Code, Section III Division 5 construction materials that are appropriate for molten salt structural applications (i.e. temperatures $\geq 600^{\circ} \mathrm{C}$ ) are limited. Candidate alloys include $304 \mathrm{H}, 316 \mathrm{H}, 800 \mathrm{H}$, Alloy 617 (currently being balloted by ASME code committees) and Alloy 709 (currently being tested by the U.S. Department of Energy to support ASME code qualification) [7]. Notably, most of these alloys were targeted for use in liquid metals and high temperature gas reactor systems and have not been widely assessed for performance in molten salt reactors [8].

Toward the goal of enabling MSR and FHR designs, corrosion resistant claddings offer an attractive solution to mitigate corrosion concerns and enable the use of Code qualified ASME Division 5 materials. This report assesses metals and alloys that may be effective as corrosion resistant cladding with select structural alloys. The structural alloys of interest are those capable of use at high temperatures $\geq 600^{\circ} \mathrm{C}$ for times $\geq 100,000$ hours. Potential cladding alloys were assessed based on their corrosion resistance in both chloride and fluoride based salts, physical properties, mechanical properties, nuclear performance, and resistance to environmentally assisted cracking. Additionally both thermodynamic and kinetic computational modeling were used to assess potential interactions between the base metal and the cladding. 


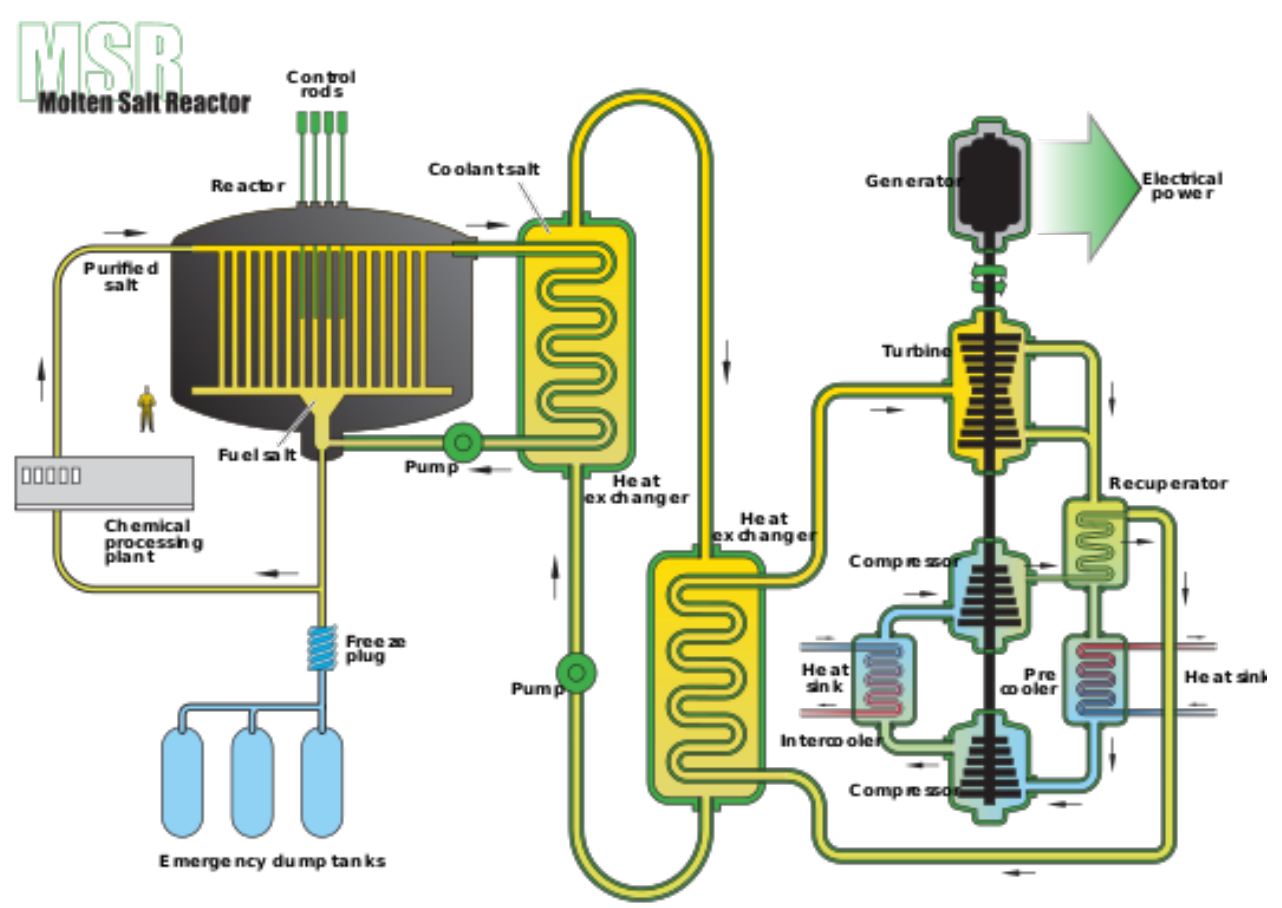

Figure 1-1. Schematic illustration of a liquid fueled molten salt reactor system from Reference [9].

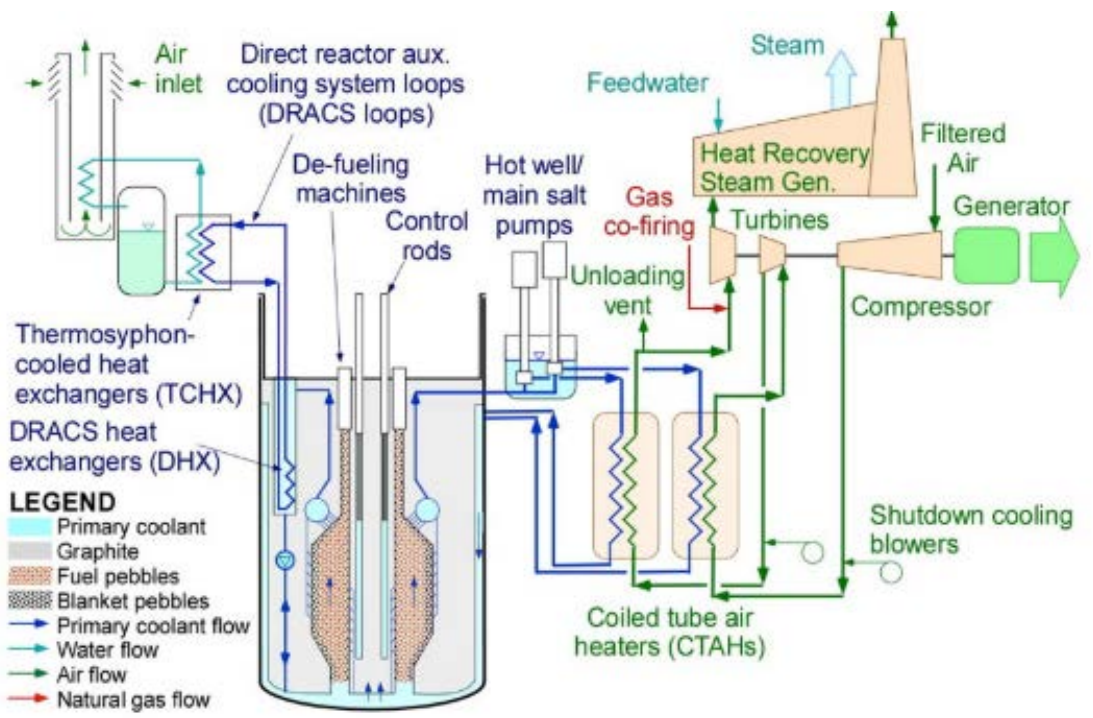

Figure 1-2. Schematic illustration of a fluoride salt-cooled high temperature reactor system from Reference [5]. 
Table 1-1. Comparison of Potential FHR and MSR Operating Conditions with Conventional LWRs [1-6]

\begin{tabular}{|c|c|c|c|c|c|c|c|}
\hline \multirow{2}{*}{ Concept } & \multirow{2}{*}{ Fuel } & \multirow{2}{*}{$\begin{array}{c}\text { Pressure } \\
\text { (MPa) }\end{array}$} & \multirow{2}{*}{$\begin{array}{c}\text { Coolant } \\
\text { Outlet } \\
\text { Temp. }\left({ }^{\circ} \mathrm{C}\right) \\
\end{array}$} & \multicolumn{2}{|c|}{ Coolants } & \multirow{2}{*}{$\begin{array}{l}\text { Estimated } \\
\text { Max. Dose } \\
\text { (dpa) }\end{array}$} & \multirow{2}{*}{$\begin{array}{l}\text { Estimated } \\
\text { Lifetime } \\
\text { (years) }\end{array}$} \\
\hline & & & & Primary & Secondary & & \\
\hline FHR & Solid & 0.1 & 700 & FLiBe & $\begin{array}{c}\text { e.g. } \mathrm{NaNO}_{3-} \\
\mathrm{KNO}_{3}\end{array}$ & 1 & $40+$ \\
\hline \multirow{2}{*}{ MSR } & Liquid & 0.1 & 700 & U-Zr-FLiBe & $\begin{array}{c}\text { e.g. } \mathrm{BeF}_{2} \\
\mathrm{NaF}\end{array}$ & 200 & $40+$ \\
\hline & Liquid & 0.1 & 700 & $\mathrm{U}-\mathrm{Cl}$ & $\begin{array}{c}\text { e.g. KCl- } \\
\mathrm{MgCl}_{2}\end{array}$ & 200 & $40+$ \\
\hline PWR & Solid & 16 & 320 & Water & Water & 100 & $60+$ \\
\hline BWR & Solid & 8 & 288 & Water & Water & 10 & $60+$ \\
\hline
\end{tabular}




\section{Results and Discussion}

Candidate metals and alloys that could be used for corrosion resistance in molten fluoride and chloride salts were first assessed based on their electrochemical potential in the salt of interest. Those metals and alloys with high (i.e. noble) corrosion potentials provide benefit to general corrosion to the structural alloy of interest based on their low thermodynamic driving force to undergo anodic dissolution. Based on their high nobility, candidate alloy systems were identified and selected alloys were further assessed based on their physical properties, mechanical properties, nuclear performance, and resistance to environmentally assisted cracking. Additionally both thermodynamic and kinetic computational modeling were used to assess potential interactions between the base metal and the cladding. The following report summarizes that down selection, compares the properties, and discusses likely benefits and challenges of using the candidate cladding materials.

\subsection{Corrosion in Molten Salts}

Corrosion of metals in molten salts is an electrochemical process whereby the metal is oxidized and another species is reduced. For example, consider equation 2.1, which illustrates how chromium can corrode while a metallic impurity in the salt (in this case iron) is reduced.

$$
\begin{aligned}
& \text { Anodic Reaction: } \mathrm{Cr} \rightarrow \mathrm{Cr}^{2+}+2 e^{-} \\
& \text {Cathodic Reaction: } \mathrm{Fe}^{2+}+2 e^{-} \rightarrow \mathrm{Fe}
\end{aligned}
$$

Recently, Shaoqiang Guo and Jinsuo Zhang have reviewed corrosion phenomena in both molten fluoride and chloride salts and have calculated redox potentials for several metals [. A comparison of the redox potentials for fluoride and chloride salts, calculated by Guo and Zhang, is shown in Figure 2-1 [10]. In Figure 2-1, the solid lines correspond to the stability of $\mathrm{M}^{\mathrm{n}+}$ where the metal dissolves and equilibrates with a $\mathrm{M}^{\mathrm{n}+}$ activity of $10^{-6}$, while dashed lines give the redox potential for the oxidants in the salts. At potentials below the solid line, the metal is thermodynamically stable and will not corrode, thus cladding with a high redox potential (i.e. the most noble metals) offer a wide range of thermodynamic stability to corrosion.

As shown for fluoride and chloride salts, the major structural alloy elements (iron, nickel, and chromium), chromium has the lowest redox potential (see red ovals) and is the least resistant to corrosion. Both experiments and calculations show that chromium exhibits higher corrosion rates than iron or nickel $[10,11]$ and preferential chromium loss from both stainless steels and nickel based alloys has been observed [11-14]. Thus, preventing chromium loss is the primary corrosion concern. 

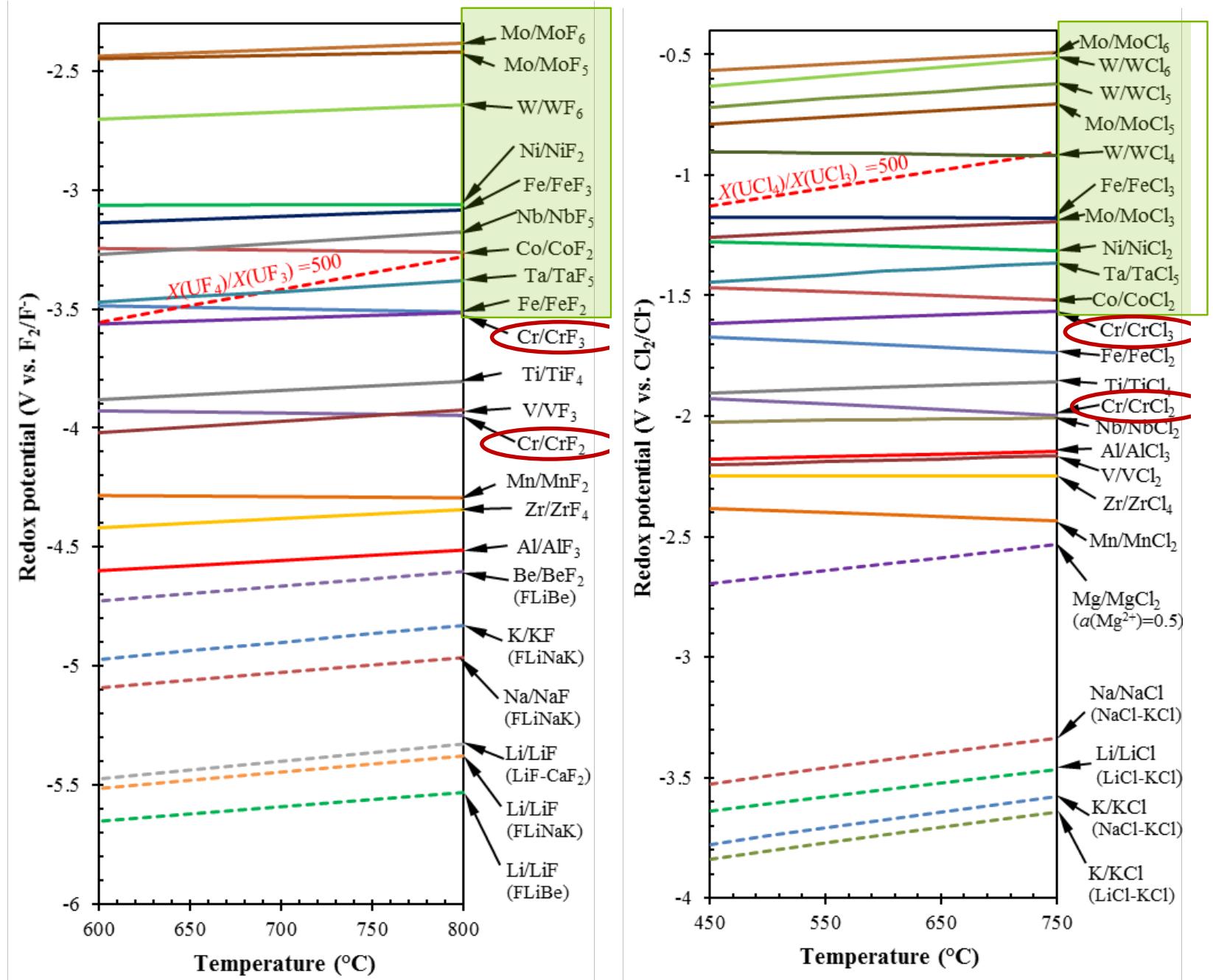

Figure 2-1. Comparison of calculated redox potentials in fluoride (left) and chloride (right) molten salt [10]. The potential of chromium is highlighted in red and metals more noble to chromium are shaded green.

Based on these thermodynamic arguments, cladding with a metal or alloy that is noble to chromium provides a wide range of thermodynamic stability. One caveat to this strategy is that care must be taken to avoid the scenario of a large cathode / small anode which could drive preferential corrosion of the anodic reaction (i.e. chromium loss). Given that concern, then potential cladding elements more noble to chromium are highlighted in green in Figure 2-1, giving the following potential candidates:

Fluoride Salts: Mo, W, Ni, Fe, Nb, Co, and Ta

Chloride Salts: Mo, W, Ni, Ta, and Co 


\subsection{Cladding selection}

Starting with the list of noble elements generated above in Section 2.1 [10] and integrating literature studies on corrosion in molten salts [12, 13, 15-27] some general comments can be made based on the periodic table. Figure 2-2 shows a portion of the transition metals that are potential cladding candidates. As noted in Figure 2-2, chromium is the primary element of concern with the fastest corrosion rates in $\mathrm{Fe}-\mathrm{Cr}$ and $\mathrm{Ni}-\mathrm{Cr}$ alloys.

The reactive metals ( $\mathrm{Ti}, \mathrm{Zr}, \mathrm{Hf}, \mathrm{V}, \mathrm{Nb}$, and $\mathrm{Ta}$ ) are not especially noble and have high solubility for interstitial elements and common salt impurities (e.g. hydrogen (tritium) and carbon in graphite moderated designs). Based on these facts, the reactive metals are likely unsuitable for corrosion resistant cladding. Experimentally, Olson et al. have investigated the corrosion of the $\mathrm{Nb}-\mathrm{Zr}$ alloy in molten FLiNaK salt at $850^{\circ} \mathrm{C}$ in graphite crucibles. The $\mathrm{Nb}-\mathrm{Zr}$ showed extensive corrosion attack and carburization [20]. Furthermore, Laurenty notes that despite tantalum being noble to chromium in fluoride salt, the corrosion product $\mathrm{TaF}_{5}$ has high solubility in the salt such that solubility driven mass loss can be appreciable [28].

As shown in Figure 2-1, the refractory metals molybdenum and tungsten are very noble in both fluoride and chloride salts. However, these metals and their alloys are body centered cubic with limited solubility in common face centered cubic structural metals. Furthermore, these alloys have modest ductility and low toughness at low homologous temperatures. Alloying additions of rhenium can increase the ductility of both molybdenum and tungsten but the benefits are modest [29] and large additions of rhenium can degrade irradiation resistance as discussed later in this report [30, 31]. Thus while desirable for corrosion, fabricating structures with molybdenum or tungsten cladding and ensuring their long term performance will be challenging.

The Group 8 metals ( $\mathrm{Fe}, \mathrm{Co}$, and $\mathrm{Ni}$ ) are ductile, but only nickel provides significant corrosion benefit in both fluoride and chloride salts $[10,19]$. Also, both cobalt and nickel can transmute with irradiation and become embrittled. Pure cobalt is hexagonal close packed with somewhat limited solubility for iron and chromium. Lastly, copper is relatively noble [27] and has demonstrated good corrosion resistance in fluoride salt (e.g. sample baskets made of OFHC copper were used in the molten salt reactor experiment (MSRE)). While OFHC copper was generally considered to have good corrosion performance in the MSRE [15, 25, 27], one sample basket (deformed during attempts to retrieve it and exposed to fuel salt for 13,025 hours) showed extensive intergranular cracking [25]. Furthermore, copper introduces a fabrication concerns, i.e. it is well known to cause liquation type cracking in several iron based alloys including austenitic stainless steels [32]. 


\section{GENERAL METALLURGY Tradeoffs with several potential metals}

Cu corrosion resistant in $F$ but IG cracking when exposed to fuel salt

Group 8 metals are ductile but only

Cr has high corrosion rate in salts

Reactive metals have high solubility for interstitial elements $(\mathrm{H}, \mathrm{C}, \mathrm{N}, \mathrm{O})-$ may not be suitable for graphite moderated cores or fluoride based salts (tritium)

\begin{tabular}{|c|c|c|c|c|c|c|c|}
\hline 22 & 23 & $\begin{array}{l}24 \\
\mathrm{Cr}\end{array}$ & $\begin{array}{l}25 \\
\mathrm{Mn}\end{array}$ & $\begin{array}{l}26 \\
\mathrm{Fe}\end{array}$ & $\begin{array}{l}27 \\
\text { Co }\end{array}$ & 28 & $\begin{array}{l}29 \\
\mathrm{Cu}\end{array}$ \\
\hline $\begin{array}{l}40 \\
\mathrm{Zr}\end{array}$ & & & $\begin{array}{l}43 \\
\text { TC }\end{array}$ & & & & $A$ \\
\hline $\begin{array}{l}72 \\
\mathrm{Hf}\end{array}$ & $\begin{array}{l}73 \\
\mathrm{Ta} \\
\end{array}$ & $\begin{array}{l}74 \\
\text { W }\end{array}$ & $\begin{array}{l}75 \\
\operatorname{Re}\end{array}$ & $\begin{array}{l}76 \\
\text { Os } \\
\end{array}$ & $\begin{array}{l}77 \\
\text { Ir }\end{array}$ & $\begin{array}{l}78 \\
\mathrm{Pt} \\
\end{array}$ & $\begin{array}{l}7 \mathrm{c} \\
\mathrm{A} \mathrm{c}\end{array}$ \\
\hline $\begin{array}{c}104 \\
\text { Rf }\end{array}$ & $\begin{array}{l}105 \\
\mathrm{Db}\end{array}$ & $\begin{array}{l}106 \\
\mathrm{Sg}\end{array}$ & $\begin{array}{c}107 \\
\mathrm{Bh}\end{array}$ & $\begin{array}{c}108 \\
\mathrm{Hs}\end{array}$ & $\begin{array}{l}109 \\
\mathrm{Mt}\end{array}$ & $\begin{array}{l}110 \\
\text { Ds }\end{array}$ & $\begin{array}{l}11 \\
\mathrm{Rg}\end{array}$ \\
\hline
\end{tabular}

Refractory metals $\mathrm{W}$ and Mo are noble in salts but limited ductility and solubility in FCC base metals
Ni provides

significant

corrosion benefit in both $\mathrm{Cl} \& \mathrm{~F}$ salts, Co \& Ni transmute with irradiation

Re can increase ductility of Mo \& W but limited benefit and may degrade resistance to irradiation

Figure 2-2. Summary of tradeoffs with several metals that could be used for corrosion resistant cladding 
Based on the initial review above, three candidate alloy systems are recommended for further assessment as described below in Table 2-1: molybdenum, tungsten, and nickel based alloys based on their nobility in both fluoride and chloride salts. Furthermore, tungsten and its alloys can act as an appreciable barrier to tritium release to the environment, which may be another key benefit for some reactor concepts. The limited ductility of molybdenum and tungsten, their body centered cubic crystal structure and irradiation performance are likely challenges for those refractory alloys, while the irradiation performance (notably helium embrittlement) is a key concern for nickel or nickel-based alloys.

Table 2-1. Summary of Potential Metals Considered for Corrosion Resistant Cladding in Molten Salt Reactor Applications.

\begin{tabular}{|c|l|c|}
\hline $\begin{array}{c}\text { Element or } \\
\text { Alloy Base }\end{array}$ & \multicolumn{1}{|c|}{ Comments } & Conclusion \\
\hline Mo & Noble in both F and Cl salts, BCC, limited ductility & Assess \\
\hline $\mathbf{W}$ & $\begin{array}{l}\text { Noble in both F and Cl salts, BCC, limited ductility. Also is } \\
\text { a tritium permeation barrier }\end{array}$ & Assess \\
\hline Ni & $\begin{array}{l}\text { Noble in both F and Cl salts, FCC, ductile, transmutes to } \\
\text { He with irradiation }\end{array}$ & Assess \\
\hline $\mathrm{Nb}$ & $\begin{array}{l}\text { Noble in F salts, BCC but ductile, reactive metal with high H } \\
\text { and C solubility }\end{array}$ & $\mathrm{X}$ \\
\hline $\mathrm{Co}$ & $\begin{array}{l}\text { Marginal nobility in Cl salts may have benefit in F salts, } \\
\text { transmutes with irradiation }\end{array}$ & $\mathrm{X}$ \\
\hline $\mathrm{Ta}$ & $\begin{array}{l}\text { Noble in F salts but TaF has high solubility, BCC but ductile, } \\
\text { reactive metal with high H and C solubility }\end{array}$ & $\mathrm{X}$ \\
\hline $\mathrm{Cu}$ & $\begin{array}{l}\text { Corrosion resistant in F salt and noble in Cl salt but can cause } \\
\text { weldability issues with austenitic stainless steels. When } \\
\text { exposed to fuel salt, MSRE showed extensive IG cracking of } \\
\text { OFHC Cu sample capsule [15, 25, 33] }\end{array}$ & $\mathrm{X}$ \\
\hline $\mathrm{Fe}$ & $\begin{array}{c}\text { Least noble in F salt, anodic to Cr/CrCl } \\
3\end{array}$ \\
\hline $\mathrm{V}$ & $\begin{array}{l}\text { No benefit in terms of nobility, reactive metals with high H } \\
\text { and C solubility. May have some potential in 'high entropy' } \\
\text { alloys - needs further assessment }\end{array}$ & $\mathrm{X}$ \\
\hline
\end{tabular}


Given these three alloy systems, five candidate alloys are recommended for further assessment: (1) Mo-TZM, (2) commercially pure tungsten, (3) a dilute W-(3-5)Re alloy for added ductility and potentially improved nuclear performance, (4) Ni-201, and (5) Hastelloy N or a similar Ni-low chromium alloy. These recommendations are summarize below in Table 2-2

Table 2-2. Recommended Alloys to Assess as Corrosion Resistant Cladding for Molten Salt Reactor Applications.

\begin{tabular}{|c|l|c|}
\hline $\begin{array}{c}\text { Element or } \\
\text { Alloy Base }\end{array}$ & \multicolumn{1}{|c|}{ Comments } & $\begin{array}{c}\text { Recommended } \\
\text { Alloy }\end{array}$ \\
\hline Mo & $\begin{array}{l}\text { Mo-TZM is commercially available. For ductility benefit, } \\
\text { large additions of Re are required ( 50\%) which likely results } \\
\text { in nuclear penalty via Re(n, } \gamma) \rightarrow \text { Os }\end{array}$ & Mo-TZM \\
\hline W & $\begin{array}{l}\text { Commercially pure tungsten is commercially available. } \\
\text { Recent research indicates that dilute W-(1-5)Re alloys [31] }\end{array}$ & W (CP) \\
\cline { 3 - 4 } Ni & $\begin{array}{l}\text { Ni-201 is commercially available and low carbon minimizes } \\
\text { embrittlement with thermal aging. Low chromium (Hastelloy } \\
\text { N) developed for MSRE with good experience [34]. Variants } \\
\text { may have alloying to mitigate tellurium embrittlement [24]. }\end{array}$ & $\begin{array}{c}\text { Hastelloy N or } \\
\text { variant }\end{array}$ \\
\hline
\end{tabular}




\subsection{Physical Properties}

Table 2-3 compares and contrasts selected physical properties of the candidate cladding alloys and example structural alloys that either are approved $(316 \mathrm{H}$ and $800 \mathrm{H})$ or are undergoing approval (Alloy 617) for high temperature use by the ASME. Notably, the physical properties of molybdenum and tungsten based alloys are significantly different than the structural alloys that they could be used with. Specifically, they melt at much higher temperatures (complicating fusion welding), are of a different crystal structure (BCC vs. FCC) and have a much smaller coefficient of thermal expansion (which could result in significant thermally induced stress). Additionally, tungsten alloys have a larger thermal neutron cross section relative to nickel (4.5 Barns) or iron (2.6 Barns). Cladding with Ni-201 or a variant of Hastelloy $\mathrm{N}$ ensures similar physical properties to the FCC nickel or iron based structural alloys.

Table 2-3. Comparison of Physical Properties of Candidate Cladding Alloys and Structural Alloys [29, 34-38].

\begin{tabular}{|c|c|c|c|c|c|}
\hline Alloy & $\begin{array}{c}\text { Melting } \\
\text { Range } \\
\left({ }^{\circ} \mathrm{C}\right)\end{array}$ & $\begin{array}{l}\text { Crystal } \\
\text { Structure }\end{array}$ & $\begin{array}{c}\text { Thermal } \\
\text { Conductivity } \\
\text { at } 25^{\circ} \mathrm{C}(\mathrm{W} / \mathrm{m}- \\
\mathrm{K})\end{array}$ & $\begin{array}{c}\mathrm{CTE} \text { at } 25^{\circ} \mathrm{C} \\
\left(10^{-6} / \mathrm{K}\right)\end{array}$ & $\begin{array}{c}\text { Thermal } \\
\text { Neutron } \\
\text { Cross Section } \\
\text { (Barns) }\end{array}$ \\
\hline \multicolumn{6}{|c|}{ Candidate Cladding } \\
\hline Мо-TZM & 2623 & BCC & 142 & 4.8 & 2.6 \\
\hline $\mathrm{W}(\mathrm{CP})$ & 3422 & BCC & 160 & 4.5 & 18.4 \\
\hline W-(3-5)Re & $3300-3350$ & BCC & 70 & 4.5 & 21.8 \\
\hline Ni-201 & $1435-1446$ & FCC & 79.3 & 13.2 & 4.5 \\
\hline Hast $\mathrm{N}$ & $1300-1400$ & FCC & 13.1 & 13.0 & --- \\
\hline \multicolumn{6}{|c|}{ Example Structural Alloys } \\
\hline $316 \mathrm{H}$ & $1375-1400$ & FCC & 15.0 & 16.0 & --- \\
\hline $800 \mathrm{H}$ & $1357-1385$ & FCC & 10.6 & 14.2 & --- \\
\hline Alloy 617 & $1332-1380$ & FCC & 13.4 & 11.6 & --- \\
\hline
\end{tabular}




\subsection{Mechanical Properties}

The elastic modulus, ductile to brittle transition temperature (DBTT) and tensile properties of candidate cladding and structural alloys are given below in Table 2-4. As shown, the BCC refractory alloys are stiffer than the structural alloys with room temperature Young's moduli of 325 GPa (Mo-TZM), 411 GPa (W-CP), 400 GPa (W-(3-5)Re) versus (196-211 GPa) for the structural alloys. Additionally, it is important to note the ductile to brittle transition temperature for the Mo and $\mathrm{W}$ based cladding (determined via tensile testing, not impact testing for $>20 \%$ reduction in area). As shown in the table, the DBTT for Mo-TZM is near room temperature but occurs $\sim 300^{\circ} \mathrm{C}$ for the tungsten alloys. Additionally, the ultimate tensile strengths of Mo and $\mathrm{W}$ are high and the tensile ductility low relative to the structural alloys.

Table 2-4. Comparison of Mechanical Properties of Candidate Cladding Alloys and Structural Alloys [29, 34-38].

\begin{tabular}{|c|c|c|c|c|}
\hline Alloy & $\begin{array}{c}\text { Young's } \\
\text { Modulus at } \\
\mathbf{2 5}^{\circ} \mathbf{C}(\mathbf{G P a})\end{array}$ & $\begin{array}{c}\text { DBTT, > 20\% } \\
\left.\text { RA ( }{ }^{\circ} \mathbf{C}\right)\end{array}$ & $\begin{array}{c}\text { UTS (MPa) at } \\
\mathbf{2 5}^{\circ} \mathbf{C}\end{array}$ & $\begin{array}{c}\text { \% Elongation } \\
\text { at 25 }\end{array}$ \\
\hline Candidate Cladding \\
\hline Mo-TZM & 325 & $\sim 25$ & 750 & $\sim 10 \%$ \\
\hline W (CP) & 411 & $\sim 300$ & $\sim 1200$ & $<1 \%$ \\
\hline W-(3-5)Re & 400 & $<300$ & $\sim 1100$ & $\sim 1 \%$ \\
\hline Ni-201 & 207 & NA & 345 & $>40 \%$ \\
\hline Hast N & 219 & NA & 800 & $40 \%$ \\
\hline Example Structural Alloys & 200 & NA & 515 & $40 \%$ \\
\hline $316 H$ & 196 & NA & 531 & $50 \%$ \\
\hline $800 H$ & 211 & NA & 734 & $60 \%$ \\
\hline Alloy 617 & & & & \\
\hline
\end{tabular}




\subsection{Performance under Irradiation}

The performance under irradiation for candidate cladding alloys is a complex topic that likely depends on the specific reactor design and the component that they are used with. While a comprehensive treatment of these effects are beyond the scope of this report, Table 2-5 details selected topics that will be of interest, including void swelling, irradiation creep, and some transmutation reactions that will be of interest.

Table 2-5. Comparison of Selected Irradiation Behavior for Candidate Cladding Alloys.

\begin{tabular}{|c|c|c|c|c|}
\hline Alloy & Void Swelling & $\begin{array}{l}\text { Irradiation } \\
\text { Creep }\end{array}$ & Transmutation & Comments \\
\hline Mo-TZM & $\begin{array}{c}<5 \% @ 10 \\
\text { dpa }\end{array}$ & \multirow{5}{*}{$\begin{array}{c}\text { Needs } \\
\text { Investigation }\end{array}$} & $\begin{array}{c}{ }^{98} \mathrm{Mo}(n, \gamma) \rightarrow \ldots .{ }^{99} \mathrm{Tc} \\
{ }^{100,101} \mathrm{Mo}(n, \gamma) \rightarrow \ldots . .{ }^{101} \mathrm{Ru}\end{array}$ & $\begin{array}{l}\text { Note appreciable } \\
\text { abundance of } \\
\text { several isotopes }\end{array}$ \\
\hline $\mathrm{W}(\mathrm{CP})$ & \multirow{2}{*}{$\begin{array}{c}<5 \% @ 10 \\
\text { dpa* }^{*}\end{array}$} & & \multirow{2}{*}{${ }^{184,186} \mathrm{~W}(n, \gamma) \rightarrow \operatorname{Re}(\rightarrow \mathrm{Os})$} & \multirow{2}{*}{$\begin{array}{l}\text { (3-5)Re may } \\
\text { suppress void } \\
\text { swelling }\end{array}$} \\
\hline W-(3-5)Re & & & & \\
\hline $\mathrm{Ni}-201$ & $\begin{array}{c}<1 \% \text { @ } 10 \\
\text { dpa } \\
0.12 \% / d p a \text { at } \\
600^{\circ} \mathrm{C}\end{array}$ & & \multirow{2}{*}{$\begin{array}{c}{ }^{58} \mathrm{Ni}+n \rightarrow{ }^{59} \mathrm{Ni}+\gamma \\
{ }^{59} \mathrm{Ni}+n \rightarrow{ }^{56} \mathrm{Fe}+{ }^{4} \mathrm{He} \\
{ }^{59} \mathrm{Ni}+n \rightarrow{ }^{56} \mathrm{Co}+\mathrm{H}\end{array}$} & $\begin{array}{l}\text { Embrittlement by } \\
\text { fission product Te } \\
\text { may be a concern }\end{array}$ \\
\hline Hast $N$ & & & & $\begin{array}{l}\text { Modified alloys } \\
\text { are resistant to Te } \\
\text { embrittlement }\end{array}$ \\
\hline
\end{tabular}




\subsection{Metallurgical Compatibility}

The metallurgical compatibility of the candidate cladding alloys and base metals is also a concern for nuclear applications. These interactions can be assessed via materials modelling as outlined in Figure 2-3. As shown, for a given base metal each of the five candidate cladding alloys can be assessed for their metallurgical compatibility via (1) Scheil solidification modelling, (2) phase stability, (3) interdiffusion kinetics and (4) solid state precipitation kinetics. The Scheil solidification modelling gives insight into the ability to fusion weld the clad onto the base metal and provides quantitative information on the solidification temperature range as well as the second phases that form during solidification. Phase stability can be explored via both experimental and computational phase diagrams. The thermodynamic phase stability is then further considered via diffusion and precipitation kinetics, which give insights into the temperature regimes and rate at which second phases form.

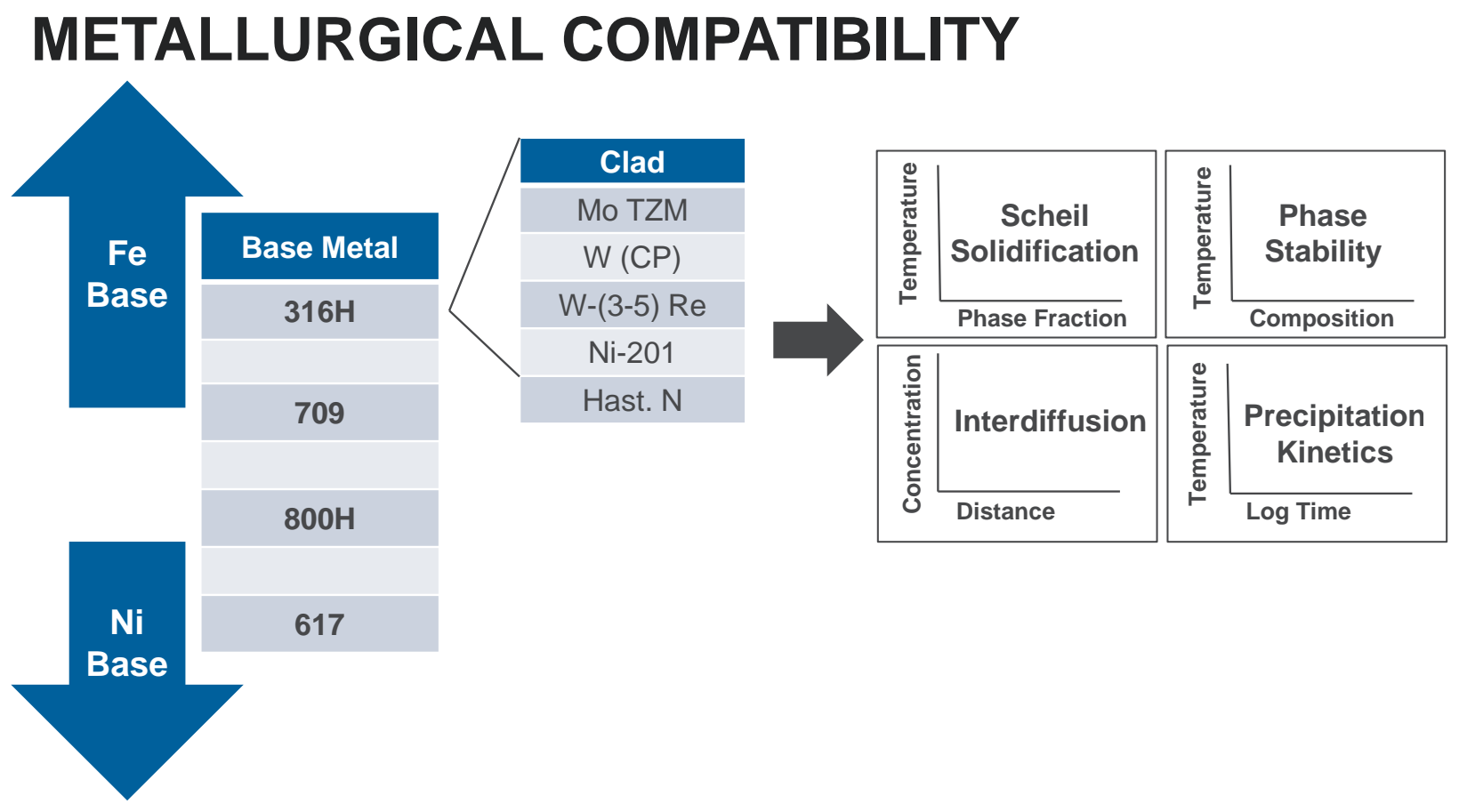

Figure 2-3. Illustration of the methodology used to assess the metallurgical compatibility of selected ASME base metals and candidate cladding alloys for corrosion resistance in molten salts. 
The phase stability of the representative base materials (iron or nickel based) and cladding alloys (nickel, molybdenum, or tungsten based) is shown in Figure 2-4. In Figure 2-4, the approximate operating temperature range of FHR's and MSR's $\left(\sim 550^{\circ} \mathrm{C}-750^{\circ} \mathrm{C}\right)$ is highlighted in red. These phase diagrams illustrate what phase is stable in the pure base metal (i.e. at an X-axis value of 1) and the effect of increasing amount of cladding alloy (moving from the right hand axis toward the left). Consider the Fe-Ni diagram, this illustrates that BCC iron is stable at MSR operating temperatures in pure iron but with increasing nickel, the FCC phase forms with a few weight \% of nickel and the FCC phase is completely stabilized at $750^{\circ} \mathrm{C}$ with $\sim 5 \mathrm{wt} . \%$ nickel. The wide range of solubility of nickel for both iron and nickel based alloys is highlighted by the green arrows.

Conversely, molybdenum and tungsten have very limited solubility in iron in this temperature range with BCC and Laves phases forming (red arrows, top row). The solubility of molybdenum and tungsten is better in nickel-based alloys with significant stability of the FCC phase before delta (Ni-Mo) or BCC (Ni-W) phases form. The calculations illustrate that Mo and W may be more compatible with nickel based alloys than stainless steels due to their greater solubility in nickel relative to iron. Of course, these are simplified calculations that required further investigation with compositions closer to the structural and cladding alloys.

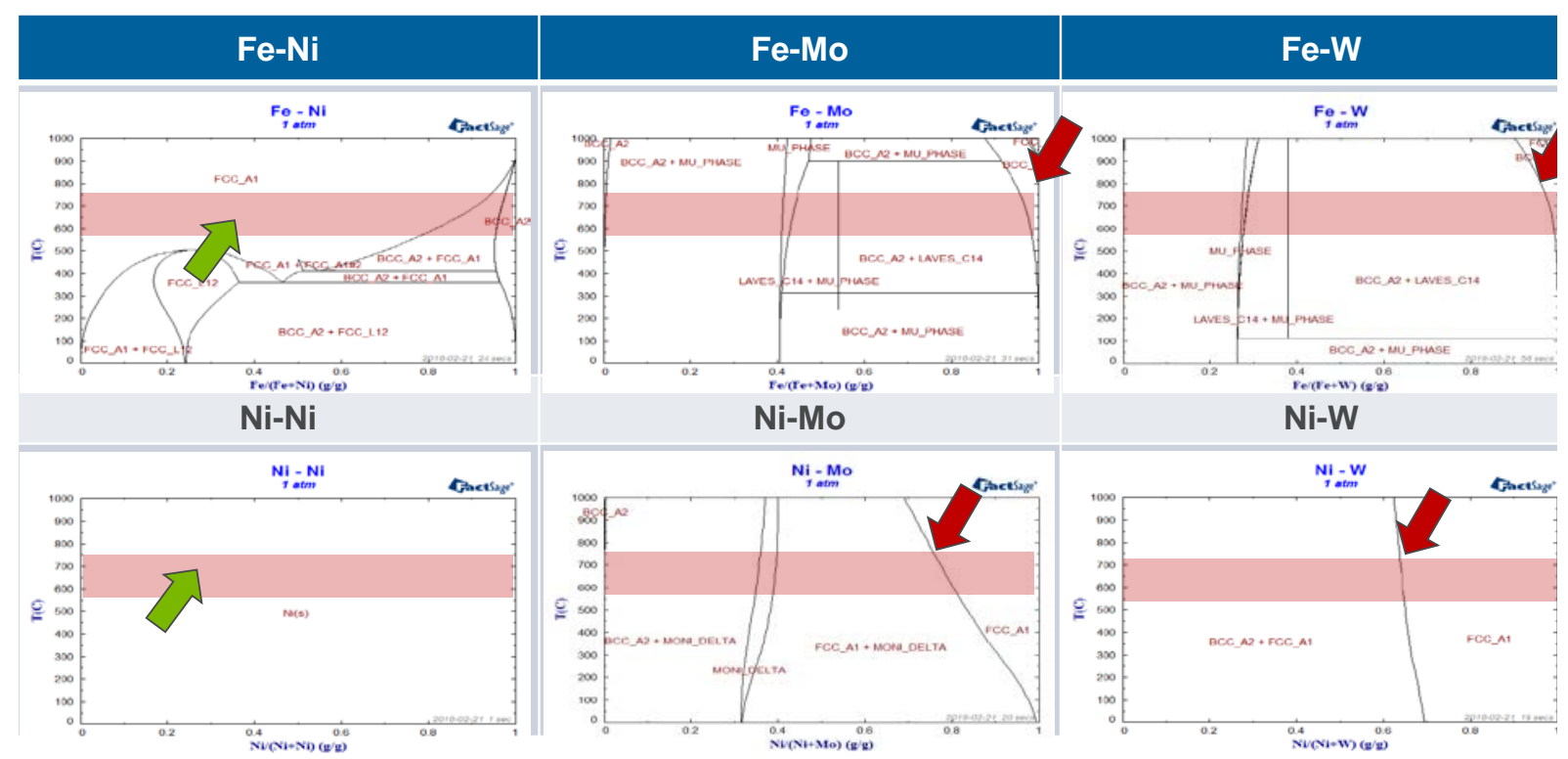

Figure 2-4. Comparison of binary phase diagrams for base metals (Fe and Ni) and candidate cladding (Ni, Mo, W) alloys. The red areas highlight FHR and MSR operating temperatures.

The next assessment of the phase stability utilizes more complex compositions. Figure 2-5 compares the solubility of nickel and molybdenum in a ternary alloy that represents 316 stainless steel (i.e. Fe-17wt.\%Cr-2.3wt.\%Mo-xx wt.\%Ni). In Figure 2-5, the left hand axis represents the pure alloy with increasing amounts of nickel (left hand plot), molybdenum (right hand plot) and the red shaded regions highlight likely operating temperatures. As shown for 316 diluted with nickel, the alloy is face centered cubic with the sigma phase also being stable and as expected nickel widens the FCC phase field. In contrast, the right hand phase diagram illustrates the 
complex effect of alloying with BCC molybdenum. As Mo dilution increases, the FCC phase field shrinks and the deleterious mu-phase is stabilized.

\section{ALLOY / CLAD PHASE DIAGRAMS}

\section{Ni has best compatibility, limited solubility of Mo}

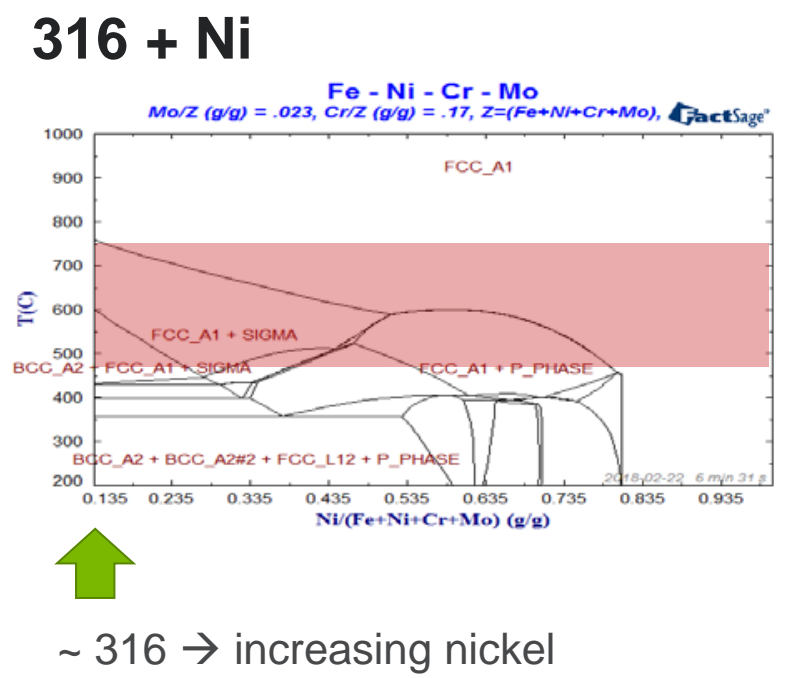

$316+$ Mo

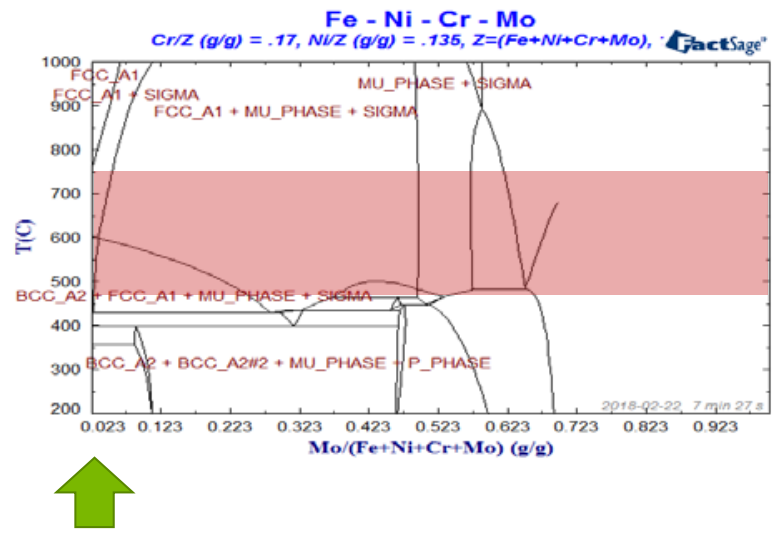

$\sim 316 \rightarrow$ increasing molybdenum

Figure 2-5. Illustration of the effects of dilution with nickel (left) and molybdenum (right) on the phase stability of a Fe-Ni-Cr alloy near the 316 stainless steel composition.

Results from a different software package (JMatPro v.10) are summarized in Figure 2-6. The left hand plots are Scheil solidification simulations illustrating the difference in behavior between $316 \mathrm{H}$ and $316 \mathrm{H}$ diluted with $20 \%$ molybdenum. As shown, molybdenum acts to widen the solidification temperature range (given by the vertical black lines) and stabilizes Laves and carbide phases during solidification. Note that large solidification temperature ranges are often associated with increased risk of solidification-type cracking during fusion welding and Laves phases can degrade mechanical properties by scavenging alloying elements and acting as void nucleation sites.

Figure 2-6 shows more complex Scheil solidification (left) and phase stability (right) lots. These calculations account for nearly the complete base metal composition, building on the predictions of Figure 2-5 that only included iron, nickel, and chromium for $316 \mathrm{H}$. Note the differences in phase stability that occur with $20 \%$ dilution with molybdenum. For example, with Mo dilution, 
there is much greater stability of ferrite (pink squares), and the embrittling sigma phase (orange diamonds) Laves phase (green circles) chi phase (gray circles) and p-phase (gray asterisks).

\section{Scheil Solidification}
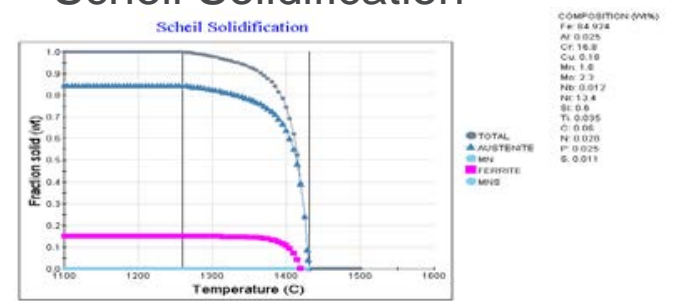

$316 \mathrm{H}$
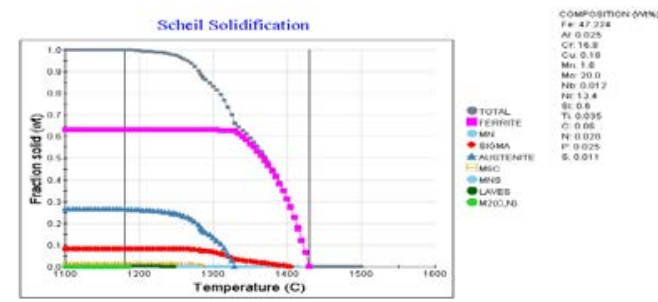
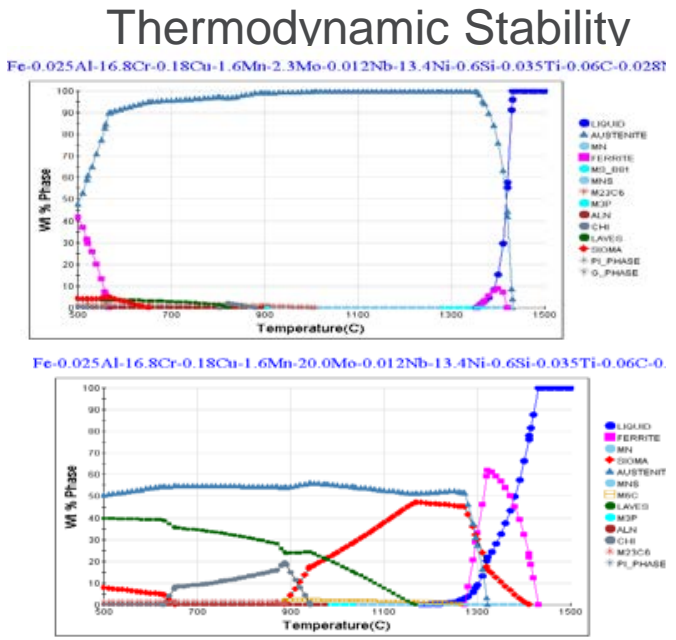

Figure 2-6. Illustration of the effects of molybdenum dilution on the solidification behavior of $316 \mathrm{H}$ (left) and on the phase stability (right).

The effect of molybdenum dilution on the time-temperature-transformation kinetics (estimated with JMatPro Software, v.10) of selected phases (sigma, chi, and Laves) is shown in Figure 2-7. The TTT kinetics of $316 \mathrm{H}$ are given on the left while the diluted alloy (addition of $20 \mathrm{wt} . \%$ Mo in total) is on the right. As shown, increased molybdenum shifts the precipitation kinetics to shorter times. Additionally, the nose of the sigma curve is moved to higher temperatures. These simulations can help guide processing to fabricate cladding as well as experiments to assess the effects of these second phases on the integrity of the corrosion resistant cladding.

$316 \mathrm{H}$
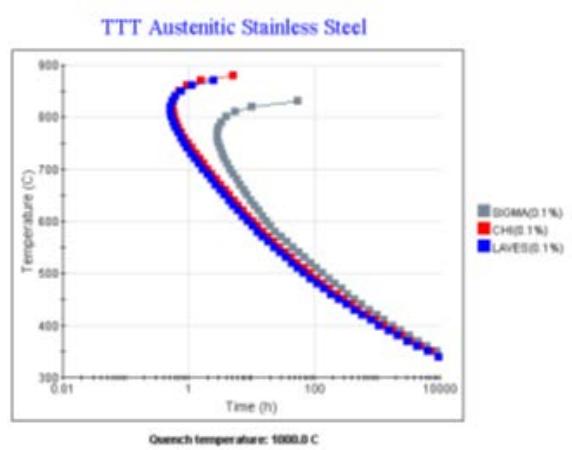

316H with 20 wt.\% Mo
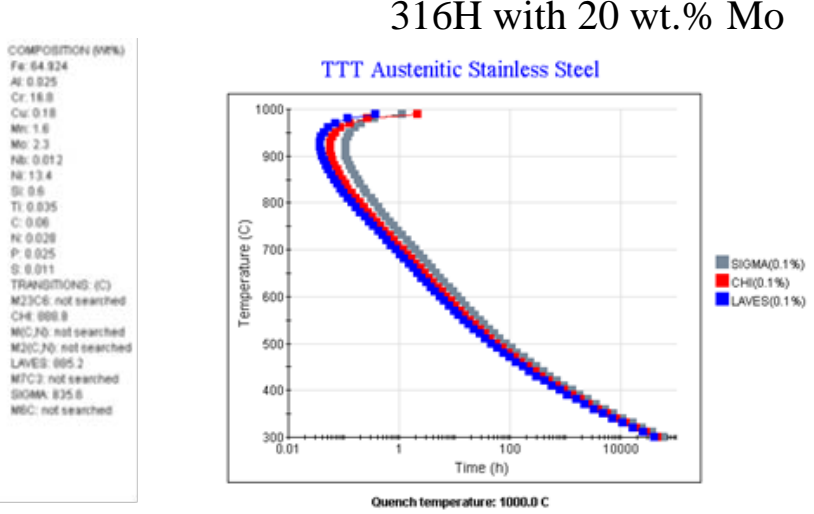

Figure 2-7. Comparison of the time-temperature-transformation kinetics for the sigma, chi, and laves phases in $316 \mathrm{H}$ stainless steel (left) with the same alloy diluted with $20 \mathrm{wt} . \%$ molybdenum (right) 


\subsection{Other Kinetic Considerations}

In addition to precipitation kinetics, other solid state mass transport phenomena need to be considered. These include chromium diffusion through the cladding and the interdiffusion rate between the cladding and the base metal. If chromium diffusion through the cladding is sufficiently fast, then degradation (e.g. grain boundary chromium loss) could still be a concern. Diffusion data for nickel, molybdenum, and tungsten are compared between $500^{\circ} \mathrm{C}$ and $700^{\circ} \mathrm{C}$ in Figure 2-8. As shown, Cr diffusion is fastest in nickel and slowest in tungsten. The diffusion rates can be used to estimate a penetration distance of chromium into nickel, molybdenum, and tungsten via an ' $\mathrm{x}=\sqrt{\mathrm{Dt}}$ 'analysis for a representative temperature $\left(700^{\circ} \mathrm{C}\right)$ and time (40 years). As shown in the right hand plot of Figure 2-8, the penetration distance into nickel is only 10 microns, $<1$ micron for molybdenum and $<<1$ micron for tungsten. This analysis shows that chromium loss through the cladding is unlikely to be a concern.
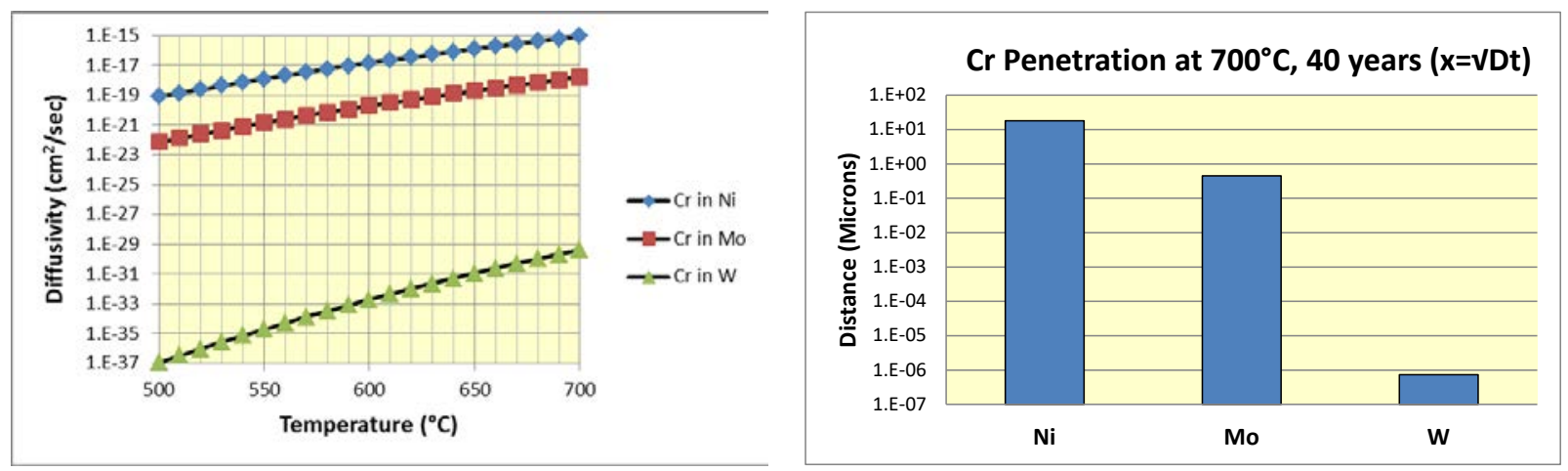

Figure 2-8. Diffusion data for nickel, molybdenum, and tungsten in chromium (left) and estimated diffusion distance after 40 years at $700^{\circ} \mathrm{C}$ (right).

In addition to chromium diffusion through the cladding, the interdiffusion rate between the base metal and the cladding is of interest (i.e. diffusion in a composite slab) [39]. This calculation helps understand both the extent of the zone that may undergo metallurgical interactions in-service (e.g. second phase precipitation) and the time scale of concern. As a first assessment of this, the interdiffusion profiles between and FCC iron $(\gamma-\mathrm{Fe})$ base material and candidate cladding metals are shown in Figure 2-9. In Figure 2-9, the diffusion profiles are estimated for a time of 60 years and a temperature of $750^{\circ} \mathrm{C}$. Consistent with their diffusivity, the potential reaction zone for nickel is on the order of \pm 100 microns from the original interface, while the slower diffusing tungsten results in a potential reaction zone of \pm 10 microns [36]. 


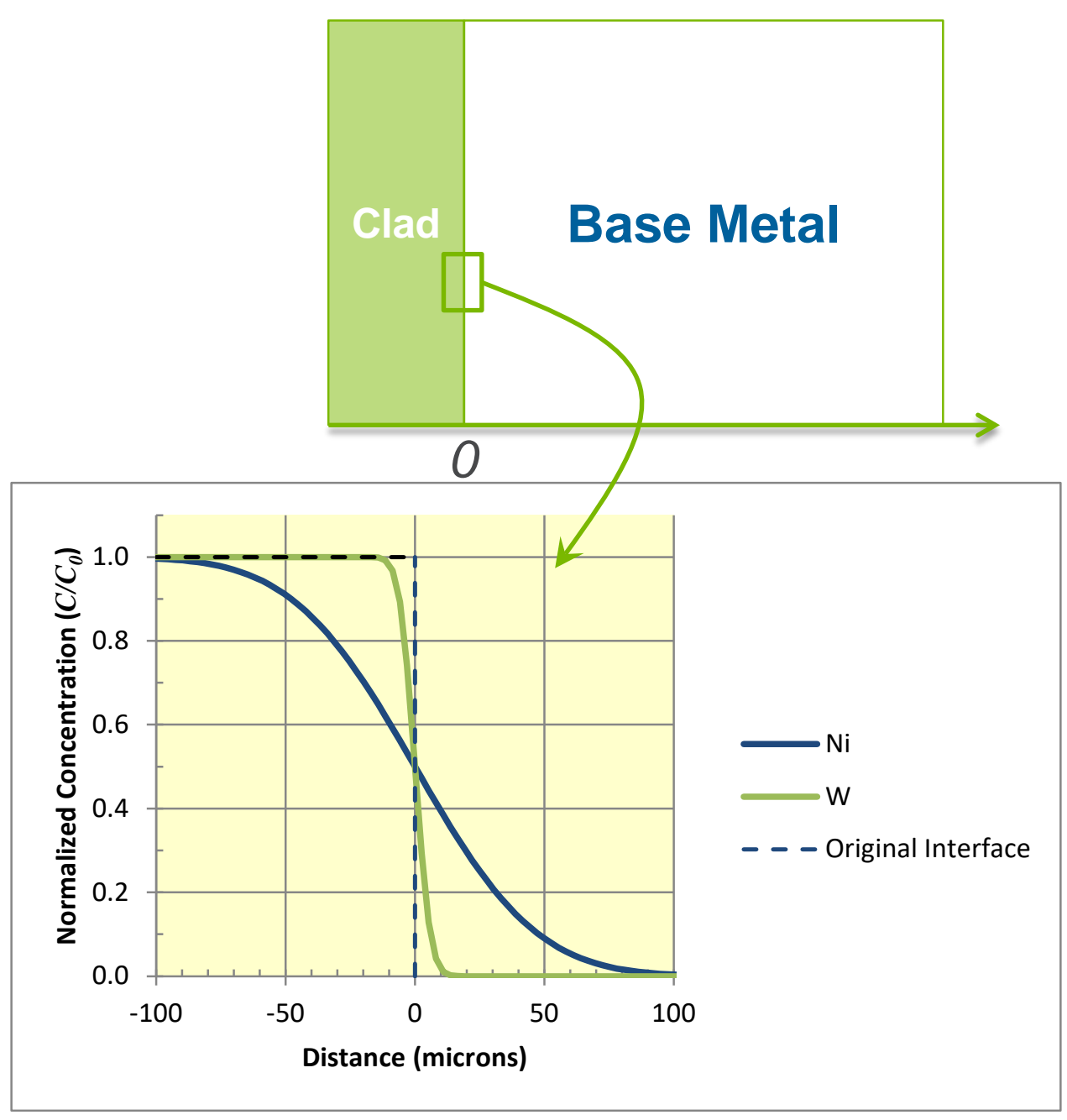

Figure 2-9. Estimated interdiffusion provides for nickel and tungsten in FCC iron after 60 years at $750^{\circ} \mathrm{C}$.

Another kinetic consideration for some reactor designs is the permeation rate of tritium through the structural alloys. Tritium is radioactive and release to the environment must be limited. Hydrogen permeation data for several metals and selected other materials are summarized in Figure 2-10 from the work of Causey, Karnesky and San Marchi [40]. As shown in Figure 2-10, hydrogen permeation through austenitic stainless steels, nickel, and molybdenum is relatively high (see black arrow). However, tungsten (and presumably dilute tungsten alloys - blue arrow) offer orders of magnitude lower permeability. Thus, in addition to being a very noble metal in fluoride and chloride salts, corrosion resistant tungsten coating have the added benefit of action as a hydrogen (tritium) permeation barrier. 


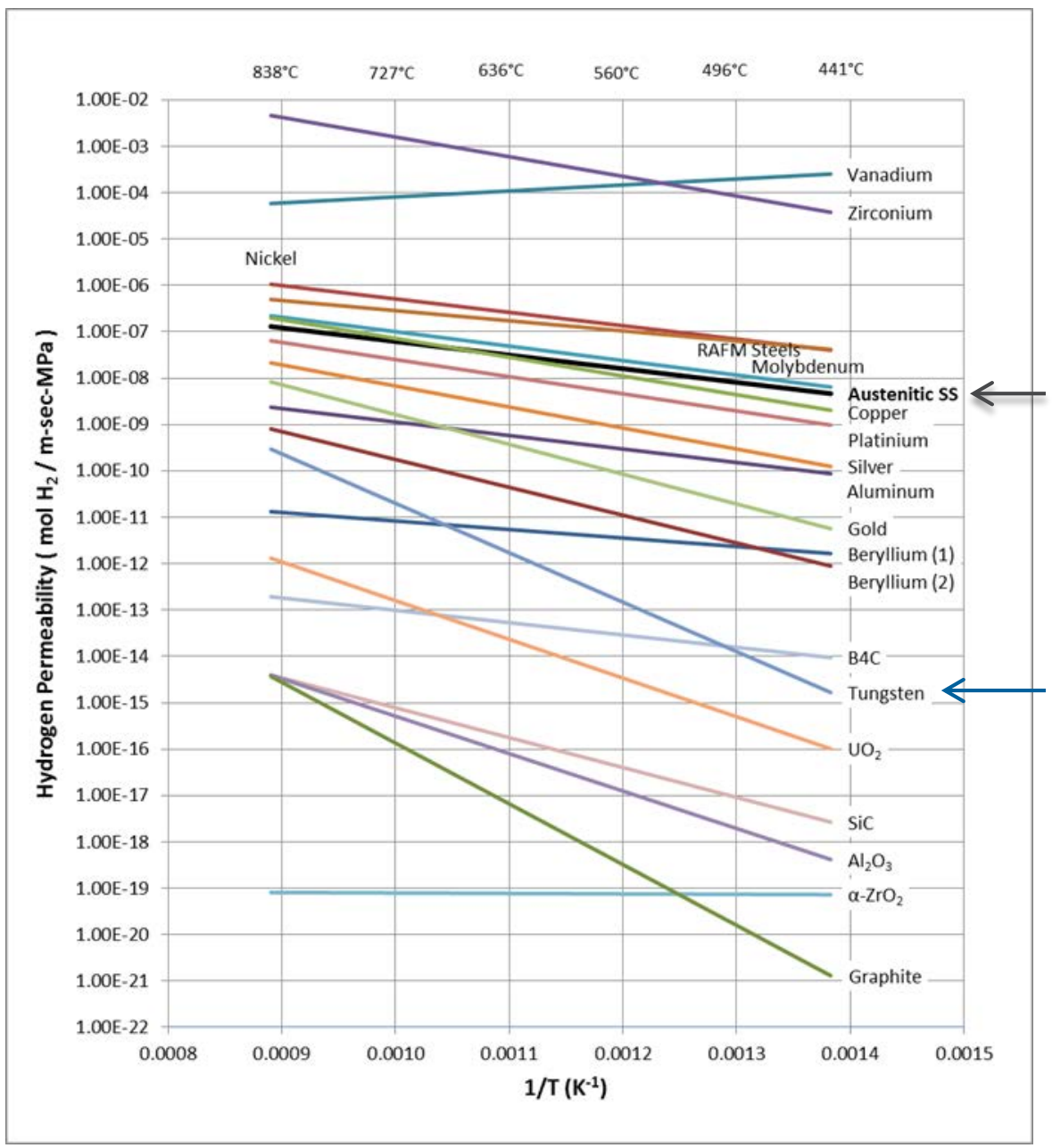

Figure 2-10. Summary of tradeoffs with several metals that could be used for corrosion resistant cladding 


\subsection{Fabrication of Cladding}

The relative ease of fabricating the candidate cladding alloys via several different industrial processes is summarized in Table 2-6. In Table 2-6, the ranking is based on engineering judgement of effectively applying the cladding to FCC iron or nickel based alloys either approved or undergoing approval for ASME Boiler and Pressure Vessel Code Section III Division 5 construction materials (i.e. 304H, 316H, 800H, Alloy 617 and Alloy 709. The rankings are given on a relative scale of five increments from likely unsuitable (black circle) to industrially proven methods (white circles).

In general, the refractory alloys are unsuitable for fusion welding due to their high melting points and low solubility in the FCC base materials. Lower temperature processes that minimize mixing (e.g. thermal spraying or brazing) are more feasible. Similarly, solid state joining processes such as explosion bonding (or friction stir application) are feasible but likely require significant development. Lower temperature processes such as sputtering or plating further minimize intermixing of the base material and cladding but typically do not produce metallic bonding between the base metal and cladding. Furthermore, the effects of thermal cycling and in-service degradation (e.g. precipitation of brittle intermetallic phases) need to be assessed.

In contrast, the Ni-201 or Hastelloy $\mathrm{N}$ variant claddings are very compatible with ASME base materials and fusion welding as well as several other industrially processes are likely viable options for cladding. Note that recent work by Feng et al. [41] has shown the feasibility of gastungsten-arc-welding nickel 201 onto 316 stainless steel. For fusion weld cladding, one consideration is process optimization to minimize the dilution of the cladding with the base material (chromium). Low dilution welding processes likely offer significant cost advantages since fewer layers of cladding will need to be applied. 
Table 2-6. Comparison of the Ability to Fabricate Candidate Corrosion Resistant Claddings via Several Industrial Processes

\begin{tabular}{|c|c|c|c|c|}
\hline & \multirow[b]{2}{*}{ CP-W / W-(3-5Re) } & \multirow[b]{2}{*}{ Mo TZM } & \multicolumn{2}{|c|}{$\begin{array}{l}\text { O: Industrially Proven } \\
\text { : : Limited Development } \\
\text { O: Significant Development } \\
\text { : : Large Scale Development } \\
\text { : Likely Unsuitable }\end{array}$} \\
\hline & & & $\mathrm{Ni}-201$ & Hast N Variant \\
\hline Fusion Arc Welding & 0 & 0 & 0 & 0 \\
\hline Advanced Fusion Welding & 0 & 0 & 0 & 0 \\
\hline Thermal Spray & 0 & 0 & 0 & 0 \\
\hline Brazing & 0 & 0 & 0 & 0 \\
\hline Explosion Bonding & 0 & 0 & 0 & 0 \\
\hline Co-extrusion or co-rolling & 0 & 0 & 0 & 0 \\
\hline Diffusion Bonding & 0 & 0 & 0 & 0 \\
\hline Vapor Deposition & 0 & 0 & 0 & 0 \\
\hline Sputtering & 0 & 0 & 0 & 0 \\
\hline Plating & 0 & 0 & 0 & - \\
\hline
\end{tabular}




\section{Summary}

The present assessment has identified three alloy systems ( $\mathrm{Ni}, \mathrm{Mo}$, and $\mathrm{W}$ ) that provide corrosion resistance in both chloride and fluoride salts of interest to advanced reactor systems. For those systems, five alloys are recommended for further investigation: Nickel-201, a modified Hastelloy N (modified to resist Te embrittlement), Mo-TZM, commercially pure tungsten and a W-(3-5 Rhenium alloy).

As discussed in the report, each of these alloy systems have advantages and disadvantages that need to be further assessed in order to develop solutions that enable application of current ASME construction materials in MSR and FHR designs.

- The nickel-based alloys Ni-201 and a modified Hastelloy N provide corrosion resistance, desirable mechanical properties, and metallurgical compatibility with ASME base materials. However, transmutation of nickel to helium is a concern and resistance to tellurium embrittlement may need to be demonstrated. These alloys are likely readily fabricable via several conventional processes.

- Both molybdenum and tungsten alloys offers very good corrosion resistance in fluoride and chloride salts. However, their high melting points, BCC structure, limited ductility, and limited solubility in FCC structural alloys present significant challenges. For their successful application, fabrication processes that minimize mixing of the base material and cladding (e.g. solid state joining processes) should be developed.

- Tungsten and dilute tungsten alloys also act as a tritium permeation barrier relative to austenitic structural alloys. The combination of corrosion resistance and a tritium barrier may offer unique benefit to some reactor designs. 


\section{Acknowledgments}

The research was sponsored by the U.S. Department of Energy, under Contract No. DE-AC0206CH11357 with Argonne National Laboratory, managed and operated by UChicago Argonne LLC. Programmatic direction was provided by the Office of Nuclear Energy.

The authors gratefully acknowledge the support provided by Alice Caponiti, Director, Office of Advanced Reactor Technologies (ART), Sue Lesica, Federal Manager, ART Advanced Materials Program, Lou Qualls of Oak Ridge National Laboratory, National Technical Director, ART Molten Salt Reactors Campaign.

The time spent by Xuan Zhang of Argonne National Laboratory in reviewing this report is greatly appreciated. 


\section{References}

1. $\quad$ Allen, T., et al., Materials Challenges for Nuclear Systems. Materials Today, 2010. 13(12): p. 1423.

2. $\quad$ Fukuya, K., Current Understanding of Radiation-Induced Degradation in Light Water Reactor Structural Materials. Journal of Nuclear Science and Technology, 2013. 50(3): p. 213-254.

3. ThorConUSA, ThorCon Power. 2018.

4. $\quad$ Latkowski, J., TerraPower and the Molten Chloride Fast Reactor. 2015.

5. $\quad$ Andreades, C., et al., Technical Description of the "Mark 1" Pebble-Bed Fluoride-Salt-Cooled High-Temperature Reactor (PB-FHR) Power Plant. 2014, U.S. DOE. p. 1-153.

6. MoltexEnergy. 2018.

7. Sham, T.-L. and K. Natesan, Code Qualification Plan for an Advanced Austenitic Stainless Steel, Alloy 709, for Sodium Fast Reactor Structural Applications, in International Conference on Fast Reactors and Related Fuel Cycles. 2017: Yekaterinburg, Russian Federation. p. 1-10.

8. Wright, R.N. and T.-L. Sham, Status of Metallic Structural Materials for Molten Salt Reactors. 2018, Idaho National Laboratory. p. 1-34.

9. A Technology Roadmap for Generation IV Nuclear Energy Systems. 2002, U.S. DOE Nuclear Energy Research Advisory Committee and the Generation IV International Forum.

10. Guo, S. and J. Zhang, Virginia Tech., private communication, 2018.

11. Xu, Y.X., Y.L. Wang, and C.L. Zeng, Electrochemical Studies of the Corrosion of Pure Fe, Ni, and $\mathrm{Cr}$ in Molten (Li,Na,K)F. High Temperature Materials Proceedings, 2014. 33(3): p. 269-276.

12. Zheng, G., et al., Corrosion of 316 Stainless Steel in High Temperature Molten $\mathrm{Li}_{2} \mathrm{BeF}_{4}(\mathrm{FLiBe})$ Salt. Journal of Nuclear Materials, 2015. 461: p. 143-150.

13. Zheng, G., et al., Corrosion-Induced Microstructural Developments in 316 Stainless Steel During Exposure to Molten $\mathrm{Li}_{2} \mathrm{BeF}_{4}$ (FLiBe) Salt. Journal of Nuclear Materials, 2016. 482: p. 147-155.

14. Jr., H.E.M., Status of Materials Development for Molten Salt Reactors. 1978, Oak Ridge National Laboratory. p. 1-38.

15. Delpech, S., et al., Molten Fluorides for Nuclear Applications. Materials Today, 2010. 13(12): p. 34-42.

16. DeVan, J.H. and R.B. Evans, Corrosion Behavior of Reactor Materials in Fluoride Salt Mixtures. 1962, Oak Ridge National Laboratory.

17. Zhang, J., Electrochemistry of Actinides and Fission Products in Molten Salts - Data Review. Journal of Nuclear Materials, 2014. 447: p. 271-284.

18. Zheng, G., et al., Investigation of $2 \mathrm{LiF}_{-} \mathrm{BeF}_{2}$ (FLiBe): Salt Transfer, Corrosion Tests, and Characterization, in Transactions of the American Nuclear Society. 2013. p. 259-260.

19. Olson, L., et al., Nickel-Plating for Active Metal Dissolution Resistance in Molten Fluoride Salts. Journal of Nuclear Materials, 2011. 411(1): p. 51-59.

20. Olson, L.C., et al., Materials Corrosion in Molten Li-NaF-KF Salt. Journal of Fluorine Chemistry, 2009. 130: p. 67-73.

21. Ouyang, F.-Y., et al., Effect of Moisture on Corrosion of Ni-Based Alloys in Molten alkali Fluoride FLiNaK Salt Environments. Journal of Nuclear Materials, 2013. 437: p. 201-207.

22. Ozeryanaya, I.N., Corrosion of Metals by Molten Salts in Heat-Treatment Processes. Metal Science and Heat Treatment, 1985. 27(3): p. 184-188.

23. McCoy, H.E., Status of Materials Development for Molten Salt Reactors. 1978, Oak Ridge National Laboratory.

24. McCoy, H.E. and B. McNabb, Intergranular Cracking of INOR-8 in the MSRE. 1972, Oak Ridge National Laboratory. p. 1-185.

25. McCoy, H.E. and B. McNabb, PostIrradiation Examination of Materials from the MSRE. 1972, Oak Ridge National Laboratory. p. 1-104. 
26. McNeese, L.E., Molten-Salt Reactor Program Semiannual Progress Report. 1976, Oak Ridge National Laboratory. p. 1-183.

27. Corrosion in Molten Salts - A Thermdynamic Approach, in Corrosion of Metals and HydrogenRelated Phenomena: Selected Topics, J. Flis, Editor. 1991, Elsevier. p. 124-150.

28. Laurenty, B., The LM-LS Experiment: Investigating Corrosion Control in Liquid Fluoride Salts by Liquid Alkali Metal, in Nuclear Engineering. 2006, University of California Berkeley. p. 1-91.

29. R.W. Buckman, J., Alloying in Refractory Metals, in Alloying, J.L. Walter, M.R. Jackson, and C.T. Sims, Editors. 1988, ASM International: USA. p. 419-445.

30. Zinkle, S.J. and F.W. Wiffen. Radiation Effects in Refractory Alloys. in Space Technology and Applications International Forum - STAIF 22004. 2004. American Institute of Physics.

31. Hasegawa, A., et al., Neutron Irradiation Effects on the Microstructural Development of Tungsten and Tungsten Alloys. Journal of Nuclear Materials, 2016. 471: p. 175-183.

32. Savage, W.F., E.P. Nippes, and M.C. Mushala, Copper-Contamination Cracking in the Weld Heat-Affected Zone. Welding Journal Research Supplement, 1978: p. 145s-152s.

33. Rosenthal, M.W., R.B. Briggs, and P.N. Haubenreich, Molten-Salt Reactor Program Semiannual Progress Report. 1971, Oak Ridge National Laboratory. p. 1-301.

34. HaynesInternational, Hastelloy N Alloy, H. International, Editor. 2017. p. 1-14.

35. Smid, I., et al., Development of Tungsten Armor and Bonding to Copper for Plasma-Interactive Components. Journal of Nuclear Materials, 1998. 258-263: p. 160-172.

36. $\quad$ Smithells Metals Reference Book. 8th ed. 2004: Elsevier.

37. SandmeyerSteelCompany. 2018.

38. $\quad$ Metals, S., Inconel 617 Materials Datasheet. 2018, Special Metals.

39. Glicksman, M.E., Diffusion in Solids: Field Theory, Solid-State-Principles, and Applications. 2000, New York: John Wiley \& Sons. 472.

40. Causey, R.A., R.A. Karnesky and C. San Marchi, Tritium barriers and tritium diffusion in fusion reactors, Comprehensive Nuclear Materials, 2012. 4: p. 511-549.

41. Feng, Z., T. Liu and Y. Wang, Initial Assessment Of Physical And Mechanical Properties Of Clad/Base Metal Systems, ORNL/TM- 2018/966, Oak Ridge National Laboratory, Oak Ridge, 


\section{ELECTRONIC DISTRIBUTION LIST}

\section{Name}

Feng, Z.

Gouger, H.D.

Hill, R.N.

Holcomb, D.E.

Keiser, J.

Lesica, S.

Li, D.

Messner, M.C.

Muralidharan, G.

Qualls, A.L.

Raiman, S.S.

Robinson, B.

Sham, T.-L.

Wang, Y.

Wright, R.N.

Zhang, $\mathrm{X}$.
Affiliation

ORNL

INL

ANL

ORNL

ORNL

DOE-NE

DOE-NE

ANL

ORNL

ORNL

ORNL

DOE-NE

ANL

ORNL

INL

ANL

\section{Email}

fengz@ornl.gov

hans.gougar@inl.gov

bobhill@anl.gov

holcombde@ornl.gov

keiserjr@ornl.gov

sue.lesica@nuclear.energy.gov

diana.li@nuclear.energy.gov

messner@anl.gov

muralidhargn@ornl.gov

quallsal@ornl.gov

raimanss@ornl.gov

brian.robinson@nuclear.energy.gov

ssham@anl.gov

wangy3@ornl.gov

richard.wright@inl.gov

xuanzhang@anl.gov 




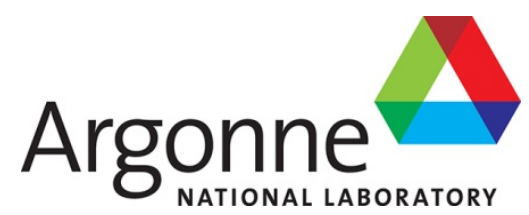

Applied Materials Division

Argonne National Laboratory

9700 South Cass Avenue, Bldg. 362

Argonne, IL 60439

www.anl.gov 